\title{
The Effect of Workforce Diversity on Organizational Performance of Selected Firms in Nigeria
}

Ogbo, Ann l.

\section{Kifordu Anyibuofu Anthony}

Department of Management, University of Nigeria, Enugu Campus annogbo@gmail.com

Wilfred I. Ukpere

Department of Industrial Psychology and people Management, University of Johannesburg, Johannesburg, Gauteng South Africa

Email: wiukpere@uj.ac.za

Doi:10.5901/mjss.2014.v5n10p231

\section{Abstract}

Workforce diversity includes the differences and similarities of the employees. Organizational performance is the extent to which the organizational objectives and goals are being achieved. Most business organizations fail in Nigeria because galvanizing diverse workforce to work as a team has been ineffective in terms of policy, training, exposure and approach to specific and overall goals. This has made profitability index difficult to measure in Nigeria. The objectives of the paper are: To determine whether workforce diversity has a positive influence on customer related issues; and to ascertain the effect of education as a tool, on the management of workforce diversity to enhance high profitability index. Findings revealed that workforce diversity has a positive effect on customer related issues in an organisation. In addition, it is found that education as a tool could be effectively utilized in managing workforce diversity to enhance high profitability. Workforce Diversity has been identified as a tool to improved organizational performance and has been as old as the first organization in Nigeria right from the barter system era of the early 1750 and at the industrial revolution and scientific management periods of 1911 to the modern epoch. A combination of the use of secondary data, oral interview, and content analysis was adopted. A spearman's rank correlation coefficient of 0.95 was obtained. Findings in line with the objectives revealed positive influence of workforce diversity on organizational performance of the selected organisations in Nigeria. Conclusion and recommendation was drawn along that regard.

Keywords: Diversity, Managing, Organizational Performance, Workforce

\section{Introduction}

The workforce is defined as the totality of the people working in an organization (Hornby 2005). Workforce diversity is defined by Kreitner and Kinichi (2004) as the multitude of the individual differences and similarities that exist among the people working in an organization. This definition is chosen because it underscores three important issues about managing workforce diversity, namely that there are many different dimensions or components of workforce diversity. This implies that workforce diversity pertains to everybody in the organization. It is not an issue of demographic characteristics such as age, race, or gender (Thomas, 2006:4). In other words, it pertains to the host of the individual differences and similarities that make all the workers in the organization unique and different from the others. In other words, workforce diversity is not synonymous with the differences of the workers. Rather, it encompasses both differences and similarities. This means that managing workforce diversity entails dealing with both simultaneously (Thomas, 2006:5). Thus, workforce diversity includes the collective mixture of differences and similarities of the workers. Dealing with workforce diversity requires managers to integrate the collective differences and similarities. Both of them have to be properly examined, determined and established (Thomas, 2006:6).

Harold and Kumar (2012) pointed out that in organizational performance index, diversity should capture practices that involve understanding and appreciating interdependence of humanity, culture, and the natural environment; practicing mutual respects for qualities and experiences that are different from our own; understanding that diversity includes not only ways of being but also ways of knowing; recognizing that personal, cultural and institutionalized 
discrimination creates and sustains privileges for some, while creating and sustaining disadvantages for others; and building alliances across differences in other for people to work together to eradicate all forms of discrimination.

Organizational performance is the extent to which the organization is achieving its goals and objectives (Osaze and Anao, 2000). Shell (2010) explains organizational performance as the extent to which the organization is fulfilling the promises it has made to its shareholders. Krietner and Kinichi (2004), observed that managing workforce diversity is very important in harmonizing the differences and similarities of workers so that the organization and the individuals within them can achieve their goals and objectives. Dressler (2006) has observed that managing workforce diversity means minimizing diversity's potential barriers such as prejudices and bias that can undermine the functioning of a diverse workforce. In practice, workforce diversity management involves both compulsory and voluntary management actions. There are many legally mandated actions that employers must take to minimize employment discrimination. In Nigeria, for example there is the Federal Character Law which stipulates that recruitments in Federal Government Agencies and Parastatals must reflect the Federal character. But many CEO's recruit to favour their own people to the detriments of other Nigerians from other places. This is unethical and tends to negatively affect the performance level of most organizations in Nigeria.

\section{Problem Statement}

The discriminatory attitude of some workforce, individual identity, lack of cooperation amongst workers has been extended by workers in same diverse organization beyond limits, which dampens morale with negative performance index. This is because departmental goals are pursued more at the expense of broad organizational goals and objectives. Corporate profitability dwindles because the core values of diversity are not properly harnessed. Similarly, nature of education, training and exposure as a policy issue has left much to be desired on the part of management. This corporate business process in relation to how best global best practice could be applied to achieve profitability is found wanting in these organizations. These performance parameters will be reviewed in this paper to unravel how best workforce diversity can boost organizational performance.

\section{Research Questions}

The statement above triggered the following research questions:

- Does workforce diversity have a positive effect on customers' related issues in Nigeria?

- What are organizations in Nigeria doing to effectively manage diversity?

- To what extent does education as a tool influence the management of workforce diversity and its effect on the profitability index of organisations in Nigeria?

\section{Objectives of the Study}

The objectives of the paper are:

- To determine whether workforce diversity has a positive effect on customers' related issues in Nigeria.

- To establish what organizations in Nigeria are doing to effectively manage diversity,

- To ascertain the extent at which education as a tool influence the management of workforce diversity and its effect on the profitability index of organisations in Nigeria.

\section{Conceptual Framework}

Workforce diversity is the totality of the difference and similarities of the behavior, attitude to work, culture, religion and management styles of the workers which include managers and non-managers in business organizations in Nigeria. This difference has to be managed efficiently and effectively in order to ascertain the influence on organizational performance. In this paper, two dimensions of organizational performance are used. The first one is the extent to which the business organization achieves its goal and objectives (Osaze and Anao, 2000). The second dimension of organization performance is the extent to which the business organization fulfills its promises to its stakeholders. There two types of stakeholders include the internal and external stakeholders. The internal stakeholders are workers, managers, members of the board of directors and shareholders and the external stakeholders are customers, contractors, suppliers and the public at large. 


\section{Theory of Performance}

The theory of performance (Elger, n.d.) develops and relates six foundational concepts to form a framework that can be used to explain performance as well as performance improvements. To perform is to produce valued results. A performer can be an individual or group of people engaging in collaborative efforts. Hence, developing performance is a journey, and the level of performance describes location in the journey. Current level of performance depends holistically on six components, namely context, level of knowledge, level of skills, level of identity, personal and fixed factors. Three axioms are proposed for effective performance improvement. They involve a performance mindset, immersion in an enriching environment and engagement in reflective practice (Bransford, Brown and Cocking, 2000).

\section{The Role of Diversity Management in Organisational Performance}

Managing Workforce Diversity effectively has a positive effect on Competive Advantage. Competive advantage is an element of strategy that gives an organization a distinctive competence. This competence and advantage stem from the process in which the management of diversity positively affects organizational behaviour and effectiveness (Kreitner and Kinichi, 2004). Effectiveness which entails doing things right is an organizational performance factor (Unyimadu, 2006). Therefore, to effectively manage workforce diversity will help to lowers costs and improve employees' attitudes. Costs are lowered in three ways. Firstly, it reduces health care expenses. Secondly, it reduces absenteeism. Thirdly, employee recruiting and training expenses can be reduced by effectively managing workforce diversity (Kreitner and Kinichi, 2004). Effectively managed workforce diversity has a positive effect on sales, market share and corporate profits. This is because work force diversity is the minor image of consumer diversity. These culminate in higher sales, bigger market share and higher corporate profits (Kreitner and Kinichi, 2004).

Researchers such as Hofstede (cited in Schultz et al., 2003) have revealed that work force diversity promotes creativity, innovative problem solving and productivity. This occurs through the sharing of diverse ideas and perspectives. Kanter (2006) was one of the first to investigate this relationship. She found that innovative companies deliberately used heterogeneous teams to solve problems and they employed more women and people of colour than less innovative companies. This is because diverse groups possessed a broader base of experience and perspectives (Kreitner and Kinichi, 2004). Similarly, effective education whether full or part time enhances exposure, training and development. This is what Bransford et al (2000), assert would promote understanding and congenial acceptance towards the realization of overall goals of the organization through performance.

\section{Significance of Diversity Management on Organizational Effectiveness}

Many organizations throughout Nigeria are unsure of what it takes to effectively manage diversity. This is partly due to the fact that top management only recently became aware of the combined need and importance of this issue. At this point, it is necessary to provide a framework for categorizing organizational initiatives. Researchers and practitioners have developed relevant frameworks. One was developed by Roosevelt (2006), who is a diversity expert. He identified eight generic action options that can be used to address any type of diversity issue. A second was proposed by another diversity expert, Morrison (2002). She empirically identified the specific diversity initiatives used by 16 organizations that successfully managed diversity in developed countries. This framework is reviewed in order to provide information both on broad and specific understanding on how organizations are effectively managing diversity (Kreitner and Kinichi, 2004:65). Table 1 below shows the Common Diversity Practices

Table 1: The Common Diversity Practices

\begin{tabular}{|c|l|l|l|}
\hline $\mathbf{s} / \mathbf{n}$ & \multicolumn{1}{|c|}{ Accountability Practices } & \multicolumn{1}{c|}{ Development Practices } & \multicolumn{1}{c|}{ Recruitment Practices } \\
\hline 1 & Top management's personal intervention & Diversity training programs & Targeted recruitment of nonmanagers \\
\hline 2 & Internal advocacy groups & Networks and support groups & Key outside hires \\
\hline 3 & Emphasis on EEO statistics, profiles & $\begin{array}{l}\text { Development programs for all high-potential } \\
\text { managers }\end{array}$ & $\begin{array}{l}\text { Extensive public exposure on diversity } \\
\text { (AA) }\end{array}$ \\
\hline 4 & $\begin{array}{l}\text { Inclusion of diversity in performance evaluation } \\
\text { goals, ratings }\end{array}$ & Informal networking activities & $\begin{array}{l}\text { Corporate image as liberal, progressive, or } \\
\text { benevolent }\end{array}$ \\
\hline 5 & $\begin{array}{l}\text { Inclusion of diversity in promotion decisions, } \\
\text { criteria }\end{array}$ & Job rotation & Partnerships with educational institutions \\
\hline 6 & $\begin{array}{l}\text { Inclusion of diversity in management succession } \\
\text { planning }\end{array}$ & Formal mentoring program & $\begin{array}{l}\text { Recruitment incentives such as cash } \\
\text { supplements }\end{array}$ \\
\hline
\end{tabular}




\begin{tabular}{|c|l|l|l|}
\hline 7 & Work and family policies & Informal mentoring program & Internships (such as INROADS) \\
\hline 8 & Policies against racism, sexism & $\begin{array}{l}\text { Entry development programs for all high- } \\
\text { potential new hires }\end{array}$ & $\begin{array}{l}\text { Publications or PR products that highlight } \\
\text { diversity }\end{array}$ \\
\hline 9 & Internal audit or attitude survey & $\begin{array}{l}\text { Internal training (such as personal safety or } \\
\text { language) }\end{array}$ & Targeted recruitment of managers \\
\hline 10 & Active AA/EEO committee, office & Recognition events, awards & Partnership with nontraditional \\
\hline
\end{tabular}

Source: Kreitner and Kinichi (2004).

\section{Barriers and Challenges to Organisational Management of Diversity}

There are certain common barriers to effectively manage workforce diversity. First and foremost is inaccurate stereotypes and prejudice. This barrier manifests itself with differences that are viewed as weaknesses. In turn, this promoted the view that diversity hiring will mean sacrificing competence and quality. Secondly is the lack of political savvy on the part of diverse employees. Diverse employees may not get promoted because they do not know how to 'play the game' of getting along and getting ahead in an organization. Research revealed that women and people of colour are excluded from organizational networks (Ely and Thomas, 2001:229). Thirdly, difficulty in balancing career and family is an issue. Women still assume the majority of the responsibilities associated with raising children. This makes it harder for women to work evenings and weekends or to frequently travel once they have children. Even without children in the picture, household chores take more of a woman's time than a man's time (Kanter, 2004). Fourthly is resistance to change. Effectively managing diversity entails significant organizational and personal change. In a nutshell, managing diversity is a critical component of organizational success. Case studies and limited research revealed that organizations are doomed to failure unless top management is truly committed to diversity management (Londen, 2006:33).

\section{Comparative Analysis on diversity Management in Nigeria and the USA}

The United States business environment rationale for managing diversity goes well beyond legal, social and moral reasons. The primary reason for managing diversity in the United States is the ability to grow and maintain a business in an increasingly competitive global marketplace. Verizon, the largest telecommunications company in the United States, believes in this proposition. Ivan Seidenberg, Verizon's CEO "perceives diversity as a strategic business imperative and believes in a multifaceted approach to diversity drives, Verizon's success and ability to compete. This strategy includes: acknowledging the unique needs of multicultural employees, customers, and other stakeholders; driving value for the customer; enhancing economic development for many types of businesses and communities; increasing shareholder equity; and winning in a global marketplace" (cited in Kreitner and Kinichi, 2004:52).

In Nigeria, Madjy, Rafat, and Saley (2011) carried out a study on participation in performance measurement system and level of satisfaction. The aim was to investigate the use of a variety of financial and non-financial performance measurement systems. Based on 87 corporate managers, the results indicate that performance measurement of diversity is associated with the satisfaction of performance measurement systems. In his treatise, Nwankwo (2003) wrote on implementing performance measurement system. His paper, reviewed the different organizational performance measurement system design process creating a framework for comparing alternative approach. It concludes that performance measurement was at the stage of identifying difficulties and pitfalls to be avoided based on African values and practitioners experience. Workforce demographics, which are statistical profiles of the characteristics and composition of the adult working population, are an invaluable human-resource planning aid. They enable managers to anticipate and adjust for surpluses or shortages of appropriately skilled individuals. For example, the US labour force is projected to increase by 17 million from the year, 2000 to 2010, and labour force participation rates differ by age, sex, race, and educational attainment (Fullerton and Toossi, 2001:21). These demographics reveal that organizations should devise strategies to ensure that they can find the number of qualified employees needed to meet their projected demands for labour.

All in all, organizations in the United States use diversity as a strategic advantage principle to ensure that employees contribute their full talents and abilities with great motivation and commitment. Therefore, it is as well essential for organizations in Nigeria to create an environment or culture that allows all employees to reach their full potential. Managing diversity is a critical component of creating such an organization and also reviewing trends that are creating a blossoming diverse workforce. 


\section{Research methodology \& Design}

The research made use of secondary data, oral interview and content analysis. The oral interview schedule involved six open-ended questions in which the respondents were asked whether workforce diversity or an aspect of it has an effect on organizational performance.

The population was made up of all the staff of selected three brewing companies namely Nigerian Breweries limited, 9th mile in Enugu, Guinness Breweries PIc and Bendel Breweries PIc in Benin. The population size was 1200 in the ratio of $0.5,0.4$ and 0.1 respectively. The Taro Yamane's formula was used to get a sample size of 300 . The data was presented by means of tables and a figure. The data analysis made use of theoretical analysis and percentages. Test, retest reliability was done, using a Spearman's rank correlation coefficient and, a coefficient of reliability $(r) 0.95$ was obtained indicating item consistency. A systematic sampling technique was used to obtain the sample size of 300 , thus giving the measured content validity.

\section{Data Analysis}

The 300 respondents were asked whether workforce diversity had a positive effect on customer related issues and a majority gave answers in the affirmative. They were further asked whether workforce diversity had a positive impact on the effectiveness aspect of organizational performance and most of them gave answers in the affirmative. In addition, they were asked whether workforce diversity had a positive influence in the corporate profitability aspect of organization performance and more than $90 \%$ of them gave answers in the affirmative. The 300 respondents were asked whether education as a tool was an aspect of managing diversity, and if it has a positive effect on organizational performance and more than $90 \%$ of them gave answers in the affirmative.

Table 2 shows the analysis of the responses from the objectives modeled for implementing the system's cybernetic model.

Table 2: The analysis of the responses from the respondents

\begin{tabular}{|c|c|c|c|c|c|c|c|}
\hline$s / n$ & Questions & $\begin{array}{c}\text { Yes in } \\
\text { number }\end{array}$ & $\%$ & $\begin{array}{c}\text { No in } \\
\text { number }\end{array}$ & $\%$ & $\begin{array}{l}\text { Total in } \\
\text { number }\end{array}$ & $\begin{array}{c}\text { Total in } \\
\%\end{array}$ \\
\hline 1 & $\begin{array}{l}\text { To determine whether workforce has a positive influence on customers } \\
\text { related issues; } \\
\text { i . Is recognition an aspect of satisfaction? }\end{array}$ & 298 & 99.33 & 2 & 0.67 & 300 & 100 \\
\hline & iii. Is talent an aspect of recognition? & 297 & 99.00 & 3 & 1.00 & 300 & 100 \\
\hline & iii. Is background a motivational factor? & 295 & 98.33 & 5 & 1.67 & 300 & 100 \\
\hline 2 & $\begin{array}{l}\text { To determine whether education as an aspect of managing diversity has a } \\
\text { positive influence on organizational performance; } \\
\text { i. Is qualification a discriminatory factor? }\end{array}$ & 294 & 98.00 & 6 & 2.00 & 300 & 100 \\
\hline & iii. Are workers exposed to positive training? & 293 & 97.67 & 7 & 2.33 & 300 & 100 \\
\hline & iii. Do your opinion count in decision making process? & 292 & 97.33 & 8 & 2.67 & 300 & 100 \\
\hline 3 & $\begin{array}{l}\text { To find out whether diversity has a positive influence on corporate } \\
\text { profitability aspect of organizational performance; } \\
\text { i.ls your promotion regularly backed with financial and non financial rewards? }\end{array}$ & 300 & 100 & 0 & 0 & 100 & 100 \\
\hline & iii.Is there reward for hard work in your organization? & 299 & 99.67 & 1 & 0.33 & 300 & 100 \\
\hline 9 & iii.Are you treated with some respect in your organization? & 291 & 97.00 & 9 & 3.00 & 300 & 100 \\
\hline 10 & iii. Is control an element of diversity model? & 290 & 96.67 & 10 & 3.33 & 300 & 100 \\
\hline
\end{tabular}

Source: Field Survey, 2013

From Table 2, the questions and responses from the objectives in absolute numbers and percentages are shown. The 300 respondents were asked whether workforce, recognition and talent had effect on customers satisfaction as inputs of the model in objective one, 298, 297 and 294 of them making percentages of 99.33, 99.00, 98.33, respectively affirmed to it while 2, 3, and 6 of them making percentages of $0.67,1.00,1.67$ and 2.00 respectively had a contrary opinion.

Also, in objective two, The 300 respondents were asked whether qualification, training and individual opinion had a positive effect on organizational performance, 294, 293 and 292 making percentages of 98.00, 97.67 and 97.33 respectively answered in the affirmative.

The respondents were asked whether regular promotion, reward(financial and non financial), respect and control had a positive influence on corporate profitability, 100, 99.67, 97.00 and 96.67 percentages said yes, while $0,1,9$ and 10 making percentages of $0,0.33,3.00$ and 3.33 respectively had a contrary opinion. 


\section{Findings}

Findings revealed that:

Workforce diversity had a positive influence on organizational performance in the selected firms in Nigeria, and that education as a tool in the aspect of managing workforce diversity had a positive effect on organizational profitability in Nigeria.

\section{Conclusion}

The importance of workforce diversity on organizational performance is very critical for the success of an organization. Workforce diversity has been identified to lead to improved organizational performance as a result of the broad based nature and the specialization it brings on board. Also, encouraging workers on educational pursuits and training implied that workforce diversity could make them strive to achieve organizational goals and objectives. Similarly, corporate profitability is a function of performance tied to the synergy of the similarities and differences of the employees that could make for increased revenue over cost.

\section{Recommendations}

It is recommended that diversity managers of the selected brewing companies should endeavour to enhance organizational performance, the effectiveness and corporate profitability aspects of organizational, by effectively using the educational enforcement of diversity goals and exposure of people to the aspect of managing diversity by ensuring that appropriate guides to thinking are done to formulate policies on diversity management.

\section{References}

Allen, R.S., and Montgomery, K.A. (2001). Applying an Organizational Development Approach to Creating Diversity. Organizational Dynamics, page 149-161.

Bransford. J.D., Brown A.L., Cocking R.R.(Eds) (2000). How people learn: Brain, Mind, Experience and School. Washington D.C: National Academy Press.

Chartered Institute of Management Accountants (CIMA) (2008) Performance Measurement Topic; Gateway Series, No 9, (online) Available: www.cimaglobal.com/documents (Retrieved on 19 March, 2014).

Collingwood, H. (1996). Who Handles a Diverse Work Force best? Working Women, February 1996, p.25.

Dressler, G. (2006). A Framework for Human Resource Management, Upper Saddle River, New Jersey: Prentice-Hall.

Elger, D. (n.d). The theory of Performance. [Online] Available: http://www.webpages.uidaho.edu/ele/scholars/Results/Workshops /Facilitators Institute/Theory\%20of\%20Performance.pdf (Retrieved on 20 April 2014).

Ely, R.T., and Thomas, D.A. (2001). Cultural Diversity at Work: The Effects of Diversity Perspectives on Work Group Process and Outcomes. Administrative Science Quarterly, 5:229-273.

Emekekwe. P. (2005), Corporate Financial Management. Kinshasha: African Bureau of Educational Services.

Fullerton, H.N., and Tossi, M. (2000). Employment Outlook 2000-2010. Monthly Labour Review, 10(2001): 21-38.

Garden-Swartz, L., and Rowe, A. (2004). Diverse Teams at Work: Capitalizing on the Power of Diversity. New York: McGraw-Hill.

Gasten, E. (2001). A Description of Ford's Program: Ford Muslim Workers Organize Island, Arizma Republic, 13 December, p. D2.

Hornby, A.S. (2005). Oxford Advanced Learner's Dictionary. Oxford: Oxford University Press.

Kanter, R.M. (2006). Confidence: How winning and loosing streaks begins and ends. New York: Crown Random House

Karr, A. (1999). Work Week: A Special News Report about Life on the job and Trends taking shape there. The Wall Street Journal, 6(1):1-3.

Kreitner, R., and Kinichi, .A. (2004). Organizational Behaviour, Boston: McGraw-Hill.

Londen, M. (2006). Implementing Diversity. Chicago: Irwin.

Madjy, Z., Rafat, S., and Saleh, A. (2011). Participation in Management Systems and Levels of Satisfaction. International Journal of Business and Social Sciences, 2(8):159-169.

Morrison, A.M. (2002). The New Leaders: Guidelines on Leadership Diversity in America, San Francisco: Jossey-Bass

Nwankwo, A. (2005). Development Planning in Nigeria. Enugu: Forth Foundation Publishers.

O'brien, J.A. (2000). An Introduction to Computers in Business Management. Homeward Illinois: Richard D. Irwin Incorporated.

Osaze, B.E., and Anao, A.R. (2000). Managerial Finance. Benin City: Uniben Press.

Rynes, S., and Rosen, B. (1995). A Field Survey of Factors Affecting the Adoption and Perceived Sources of Diversity Training. Personnel Psychology, Summer, 247-270.

Schultz, H., Bagraim, J., Potgieter, T., Viegde, C. \& Werner, A. 2003. Organisational behavior. Pretoria: Van Schaik.

Thomas, R.R. (2006). Redefining Diversity. New York: AMACOM.

Unyimadu, S.O. (2006). Business Policy and Strategy. Benin City: Harmony Publishers.

Weaver, V.J. (2001). What these CEOs and Their Companies Know about Diversity", Business Week, 10September, pp. 1-20. 